\title{
Special Announcement \\ The Kuala Lumpur Declaration on Promotion of Scholarly Writing Skills and Standards in the Asia Pacific Region
}

\section{THE DECLARATION}

We, the participants in the Asia Pacific Association of Medical Journal Editors (APAME) Convention 2012, gathered in Kuala Lumpur, Malaysia, from 31 August to 3 September 2012;

\section{CONSIDERING}

That scholarly, scientific and technical health information is an invaluable resource for universal health promotion and policy development, disease prevention, diagnosis and treatment, habilitation and rehabilitation, support and palliation;

That this health must be reliable, comprehensible and available to health care providers and beneficiaries within the Asia Pacific Region and the rest of the World;

That the Western Pacific and Southeast Asian Regions of the World Health Organization together represent over 50\% of the global population, who both generate and need an enormous amount of health information;

That the Asia Pacific Association of Medical Journal Editors (APAME) is an important catalyst for the promotion of scholarly writing skills and standards that will increase the reliability, comprehensibility and availability of health information generated within the region;

\section{CONFIRM}

Our commitment to promoting quality scholarly writing skills and standards that will ensure greater access to publication by authors and researchers, especially for developing countries in the Asia-Pacific Region, elevating loco-regional research and publishing to the global arena;
Our commitment to the continuing education of researchers, authors, reviewers and editors, to empower them to write, review and edit scholarly manuscripts for publication and dissemination, thereby promoting health and well-being in the region and the world;

Our commitment to collaboration with academic societies, universities, government and non-government organisations to promote research and publication to support evidencebased policies for the betterment of health and societal development in the region and globally;

\section{COMMIT}

Ourselves, to improving our scholarly writing skills and standards, setting the example for our peers, authors, reviewers, editors and librarians in the region;

Our publications, to attaining increasing scholarly quality worthy of continued production and dissemination through analog and digital library services including, but not limited to, the Western Pacific Region Index Medicus (WPRIM), Asia Pacific Medical Journal Articles Central Archives (APAMED Central) and Global Health Library;

Our organization, the Asia Pacific Association of Medical Journal Editors, to building further networks, convening conferences, and organizing events to educate and empower editors, peer reviewers and authors to achieve and maintain internationally acceptable, but regionally appropriate, scholarly skills and standards.

(This declaration was launched at the 2012 Convention of the Asia Pacific Association of Medical Journal Editors held in Kuala Lumpur, Malaysia, 2 September 2012) 